Cómo citar este artículo / How to cite this article: Pérez Zurita, A. D. (2021). Aproximación al concepto de princeps en la obra de Tito Livio. Lucentum, XL, 271-285. https://doi.org/10.14198/LVCENTVM.18419

\title{
APROXIMACIÓN AL CONCEPTO DE PRINCEPS EN LA OBRA DE TITO LIVIO
}

\author{
AN APPROACH TO THE CONCEPT OF PRINCEPS IN LIVY'S WORKS
}

ANTONIO D. PÉREZ ZURITA

Universidad de Córdoba, España

152pezua@uco.es

https://orcid.org/0000-0003-3562-7332

Recepción: 15/12/2020

Aceptación: 25/03/2021

\section{Resumen}

En este artículo investigamos los testimonios sobre principes en la obra de Tito Livio y el heterogéneo uso del término por parte de este historiador. Ofrecemos un análisis histórico de algunos de los pasajes más relevantes en los que el historiador utiliza dicho concepto. Entre ellos destacan los contextos diplomáticos y las luchas internas entre los partidarios de establecer pactos con Roma contra los que preferían mantener su independencia o establecer alianzas con los enemigos de la ciudad lacial.

Palabras clave. Élites indígenas; principes; Tito Livio; expansionismo romano.

\begin{abstract}
In this article we look into testimonies about principes in the work of Livy and his heterogeneous use. We offer a historical analysis of some of the most relevant passages in which the historian uses this concept. These include diplomatic contexts and internal struggles among supporters of establishing pacts with Rome against those who preferred to maintain their independence or establish alliances with the enemies of the Lacial town.
\end{abstract}

Key words. Indigenous elites; principes; Titus Livius (Livy); Roman conquests.

Financiación: Estudio llevado a cabo en el marco del Proyecto de I+D de Generación de Conocimiento titulado «Funciones y vínculos de las elites municipales de la Bética. Marco jurídico, estudio documental y recuperación contextual del patrimonio epigráfico. II» (ORDO VI), con Referencia PGC2018-093507-B-100, del Programa Estatal de Generación de Conocimiento y Fortalecimiento Científico y Tecnológico del Sistema de I+D+i del Ministerio de Ciencia, Innovación y Universidades, cofinanciado por el Fondo Europeo de Desarrollo Regional. Agradecemos las aportaciones de los/as evaluadores/as del trabajo que, sin duda, han enriquecido el resultado final del mismo. 


\section{INTRODUCCIÓN}

En la literatura latina es frecuente encontrar el concepto princeps/principes para hacer referencia a una persona o a un conjunto de personas que, en principio, debemos enmarcar sociológicamente dentro de la oligarquía. Sin embargo, dicho concepto es polisémico, encerrando distintos matices según el contexto de la narración o el autor que estemos analizando. Nuestro objetivo en las próximas líneas será aportar algo de luz al uso de dicho concepto por Livio en su obra Ab Urbe condita ${ }^{1}$.

El uso del concepto que pretendemos analizar en la obra liviana supera ampliamente las trescientas referencias. Pese a que Livio, como otros autores latinos, utiliza términos análogos a éste con un significado similar a alguna de las acepciones de princeps/principes, como por ejemplo primor/primores o principal/principalis, pensamos que el análisis de los casi cuatrocientos pasajes en los que aparece aquel es más que suficiente para extraer algunas conclusiones sobre el particular ${ }^{2}$. De hecho, en no pocas ocasiones, tales términos aparecen en un mismo pasaje, muchas veces para hacer referencia a una misma persona o grupo de personas, por lo que podemos considerar que es un recurso literario del autor para evitar ser redundante o reiterativo ${ }^{3}$.

\section{PRINCIPES ROMANOS}

La primera distinción que deseamos realizar es que Livio usa el concepto princeps/principes para calificar, tanto a personas o grupos de personas que gozan de la

1. Sobre el uso de dicho concepto en distintas fuentes literarias y epigráficas en general, véase $T h L L$, s. v. «princeps». Para la realización del presente trabajo hemos utilizado la edición de J. A. Villar Vidal publicada en la editorial Gredos. Mientras que no se indique lo contrario, las referencias literarias que expondremos a continuación remitirán siempre al autor y la obra que es objeto central del análisis de este trabajo. Para concluir, son muy útiles las diferentes obras dedicadas al comentario exhaustivo de cada uno de los pasajes contenidos en la obra de Livio: R. M. Ogilvie (1965); S. P. Oakley (19992005); J. Briscoe (1973; 1981; 2008; 2012). Paralelamente, para Polibio, una de las principales fuentes de nuestro autor, véase F. W. Walbank (1957-1979). Un análisis de las fuentes de Livio, con especial atención a Polibio, en P. G. Walsh (1961: 110-137) y D. S. Levene (2010: 82-163).

2. Más allá de esta cuantificación general, no es posible ofrecer una perspectiva estadística de cada una de las categorías que expondremos a lo largo de nuestro trabajo puesto que, para que aquella fuera correcta, deberíamos conocer el significado preciso con el que Livio utiliza el concepto de princeps en cada ocasión, lo que por desgracia no siempre ocurre. Por ello, nos limitaremos a exponer algunos de los casos que creemos más significativos y que ilustran suficientemente esas mismas categorías.

3. Por poner un ejemplo, en el contexto de la última guerra entre sabinos y romanos, califica a Rómulo como primor y a Metio Curcio como princeps, para hacer referencia a quiénes encabezaban las fuerzas militares de uno y otro pueblo $(1,12,7-8)$. ciudadanía romana, como a peregrini. Las referencias a principes que eran ciudadanos romanos está en torno al centenar.

Según J. Hellegouarc'h el concepto «princeps» no servía para denominar a los senadores en general, sino únicamente a los más importantes de entre ellos, en el caso de la Urbs a los consulares o los que juegan un papel más activo en la política, incluso a los últimos defensores del mos mairoum. Así, por ejemplo, en Cicerón, se referiría a la oligarquía o la élite a la que se le confía los asuntos de Estado ${ }^{4}$. En el caso de Livio, podemos establecer una distinción entre el uso del término en singular y en plural. No cabe duda de que nuestro autor cualifica singularmente como princeps a personajes que desempeñaron un papel muy relevante en el devenir histórico de la Urbs. Así, por ejemplo, P. Valerio Publícola, cuatro veces cónsul durante los primeros años de la República romana y calificado omnium consensu princeps belli pacique $(2,16,7)^{5}$; Apio Claudio, de origen sabino y aceptado entre los patricios y en el senado de Roma, del que fue uno de sus principales (in principum dignationem: 2, 16, 5) llegó a ser cónsul en 495 a. C. y su aplicación de las leyes sobre deudas fue causa de la secessio plebis al Monte Sacro ; Marco Furio Camilo, quien, entre los siglos V y IV a. C., fue elegido dictador en cinco ocasiones, tribuno consular en otras seis, celebrando cuatro triunfos y siendo nombrado a su muerte como segundo fundador de Roma $(6,1,4 \text { y 7, 1, 9 })^{7}$; Mamerco Emilio Marmercino, calificado como el hombre más destacado de su tiempo (principem aetatis suae: 9, 34, 9), tribuno consular y tres veces dictador entre 438 y 426 a. C. ${ }^{8}$; Q. Fabio Máximo, cónsul en cinco ocasiones, dictador en otras dos y censor (230 a. C.), quien, según P. Sempronio Tuditano era, incluso a juicio de Aníbal, el primer ciudadano de Roma (principem Romanae civitatis: 27, 11, 11; también 29, 37, 1) ${ }^{9}$; y P. Cornelio Escipión Africano, dos veces cónsul, censor que, como es sabido, fue el vencedor en la batalla de Zama y que, años más tarde, junto a su hermano, logró derrotar definitivamente a Antíoco III. En sus años finales, Livio se pregunta cómo se pudo acusar al primer ciudadano de Roma y Cartago (principes inuentas: 38, 50, 7; también $38,51,10)^{10}$.

En cuanto a las referencias a los principes romanos en plural, no cabe duda de que Livio utiliza dicho concepto en ocasiones para dotar de cualidades especiales a un determinado grupo dentro de la oligarquía senatorial

\footnotetext{
4. J. Hellegouarc'h, 1972: esp. 327 ss. y 441 s. No obstante, en este sentido, habría que realizar una distinción entre las referencias a las oligarquías romanas frente a las de las comunidades de fuera de la Urbs.

5. Cfr. Broughton, 1951: 2.

6. Cfr. Broughton, 1951: 12.

7. Cfr. Broughton, 1951: 82.

8. Cfr. Broughton, 1951: 57.

9. Cfr. Broughton, 1951: 227.

10. Cfr. Broughton, 1951: 277.
} 
romana. Así, por ejemplo, al narrar la gran epidemia que azotó Roma en 463 a. C., Livio asegura que fueron afectados plerique principum patrum maios pars $(3,6$, $8)^{11}$. Asimismo, los principes no deben ser identificados directa y únicamente con los magistrados en ejercicio, sino con las personalidades más influyentes, en general de la política, en Roma. De nuevo, cuando en 472 a. C. el tribuno de la plebe Volerón Publilio presentó la propuesta de elegir a sus magistrados en comicios por tribus, los cónsules y prohombres (consulum aut principum) romanos trataron de que al menos uno de sus colegas frenase la petición mediante intercessio $(2$, $56,4)$. Sin embargo, tampoco podemos identificar a los principes con todos los miembros del senado romano, pues en la obra de Livio también se distingue a los primeros como un grupo selecto dentro del conjunto de senadores. En este caso, recién elegidos como censores M. Emilio Lépido y M. Fulvio Nobilior en 179 a. C., los senadores principales (principes senatorum) apelan a relajar la rivalidad que había entre ambos personajes por el bien de los ciudadanos $(40,45,8)$.

Otra de las acepciones de princeps/principes utilizada por Livio es la alusiva a los «primeros» senadores o «los más destacados» por su posición en el album senatorial $^{12}$. En efecto, una de las funciones más relevantes de los censores romanos era actualizar la nómina senatorial en la lectio y ordenar a los clarissimi según su rango. Como sabemos por Livio, a través de un testimonio del censor M. Cornelio Cetego, lo normal era que el excensor vivo más antiguo fuera el princeps senatus, aunque el censor al cargo de este cometido podía alterar dicho orden $(27,11,9-11)$. En estos casos, por lo tanto, el significado del término sería muy restrictivo, haciendo referencia a uno o, en todo caso, un grupo muy selecto de senadores en la Urbs. Sea como fuere, nuestro autor utiliza el término en no pocas ocasiones para hacer referencia a miembros del senado, aunque la mayor parte de las veces es difícil establecer una aproximación cuantitativa sobre el carácter más o menos restringido de clarissimi viri ${ }^{13}$. De hecho en algunos pasajes principes parece referirse con seguridad a todos los miembros del senado o, al menos, a una representación muy extensa de los mismos, si bien este sentido más genérico es cuantitativamente menos representativo en la obra del historiador patavino ${ }^{14}$.

Paralelamente, en un sentido restrictivo, aunque todo hace pensar que en menor grado, se constatan otras acepciones en la obra de Livio tales como princeps/

11. Sobre dicho episodio, véase también D. H. 9, 67-68 y Oros. hist. 2, 12.

12. Por ejemplo Liv. 5, 25, 2; 8, 14, 1; 27, 11, 9.

13. Para estos casos cfr. 2, 27, 12; 3, 68, 1; 4, 6, 6; 4, 48, 4-15; $4,49,1 ; 4,59,11 ; 5,41,7-10 ; 6,5,6 ; 6,11,3 ; 6,32,3 ; 8$, 33,$9 ; 10,11,3 ; 22,34,2 ; 26,18,6 ; 26,22,14 ; 29,19,3 ; 30$, 26,$12 ; 40,46,15 ; 45,20,10 ; 45,36,10$.

14. En este caso 5, 25, 11; 5, 30, 4; 26, 36, 3 . principes civitatis ${ }^{15}$, principes iuventutis ${ }^{16}$ o principes plebis $^{17}$.

Tito Livio utiliza también el concepto que estamos analizando para designar a los personajes más relevantes o destacados dentro de un colegio u organismo colegiado. En este sentido, nuestro historiador cita a Quinto Fabio y Apio Claudio como principes inter decemviros $(3,41,8)$.

Asimismo, el escritor patavino usa este calificativo para designar a los representantes más cualificados de un conjunto de romanos que hubieran caído como rehenes en el contexto de expansión por el Mediterráneo o de las embajadas para negociar con el enemigo condiciones para la paz o para una rendición lo más honrosa posible. Este último caso es el significado que debemos deducir de la legatio que encabezó L. Lentulo para buscar la mejor salida para los romanos atrapados en las Horcas Caudinas ${ }^{18}$. En cuanto a grupos de rehenes romanos, se califica como principes, tanto al representante de los prisioneros romanos que habló ante el senado para transmitir las condiciones del rescate impuestas por Aníbal tras la batalla de Cannas (22, 59, 1), como a los rehenes más importantes que estaban en manos de Perseo tras su victoria ante los romanos en Iliria ${ }^{19}$.

Un contexto en buena parte distinto del que estamos analizando, es el empleo de princeps/principes desde un punto de vista militar. En este sentido, los militares así adjetivados pueden serlo como cabecillas de un movimiento sedicioso ${ }^{20}$ o como jefes de una guarnición ${ }^{21}$. No obstante, en este caso, Livio suele utilizar el concepto con un significado más concreto y técnico, como es el que tienen los principes cuando se refieren a las fuerzas militares que luchaban detrás de los hastati (cfr. 8, 8,6)-acompañados posteriormente en el tiempo por los velites en primera línea- y que jugaban un rol decisivo en la batalla pues, tras afrontar estos últimos la primera acometida del choque, los principes, soldados con las condiciones y el armamento más idóneos para el combate, eran los que soportaban el peso de la batalla y sobre los que recaía fundamentalmente la

15. Así, 3, 1, 3; 3, 12, 1; 25, 4, 4; 33, 45, 6; 38, 10, 3; 40, 46, 14; $43,14,1 ; 43,16,14 ; 45,36,7$.

16. Por ejemplo: $2,12,15 ; 9,14,16 ; 22,53,5$ (referido, en este caso, concretamente, a L. Cecilio Metelo); 42, 61, 5.

17. Entre ellos, 4, 7, 9; 4, 25, 9; 6, 34, 3.

18. 9, 4, 7 donde Léntulo es calificado princeps legatorum virtute atque honoribus erat, en este caso porque, como sabemos por el propio Livio, el personaje había desempeñado el consulado (cfr. 8, 22, 8).

19. $7,13,2 ; 43,19,2$.

20. P. ej. $28,24,13$ y $28,26,5$. En un contexto no militar, pero igualmente contrario a las leyes y las normas, cfr. 24, 18, 3 .

21. P. ej. 28, 25, 5. Recordemos igualmente que el sabino Metio Curcio es calificado como princeps en el sentido de ser el que encabezaba a los sabinos frente a las tropas de Rómulo $(1,12,7-8)$. 
responsabilidad de diezmar gravemente o de vencer al enemigo $^{22}$.

Para finalizar, el concepto que estamos analizando es utilizado por Livio de forma más esporádica para hacer referencia al antepasado más ilustre de una familia ${ }^{23}$; al círculo más cercano a ciertos personajes que jugaron un papel importante en ciertos momentos de la historia de Roma y que actuaban generalmente como «consejeros» ${ }^{24}$; o al personaje que encabeza un grupo de opinión dentro del senado romano ${ }^{25}$.

\section{PRINCIPES PEREGRINOS}

Contamos con casi trescientos pasajes en los que Tito Livio usa el concepto de princeps/principes para calificar a personajes peregrini en el $A b$ Urbe condita, por lo que, al menos cuantitativamente hablando, el autor patavino emplea dicho concepto con mucha mayor asiduidad en este contexto si lo comparamos con el de los ciudadanos romanos, que acabamos de analizar. En concreto, podemos establecer una proporción de en torno a $4: 1$.

Como ya advertimos anteriormente, Livio suele utilizar este calificativo con mayor frecuencia que otros como primor/primores o principal/principalis, si bien, de nuevo, al menos en general, con un significado muy parecido. Asimismo, como notará el lector a continuación, el uso de princeps/principes para adjetivar a personajes peregrinos es polisémico y, en muchas ocasiones, con connotaciones muy parecidas a las ya analizadas anteriormente, si bien su frecuencia varía con respecto al apartado anterior.

Siguiendo el mismo esquema aplicado supra-siempre que la fuente que estamos analizando lo permita-, Livio utiliza el concepto princeps de modo absoluto para citar a personajes peregrinos que tenían una relevancia especial dentro de su comunidad. Así, por ejemplo, denomina a Servio Tulio - a la sazón, padre del sexto rey de Roma-, quien según el historiador era el personaje más importante de la ciudad latina de Cornículo $(1,39,5)$; de Octavio Mamilio Tusculano,

22. Los principes iban armados con casco, scutum pesado, pilum y espada. Ver descripción y táctica en Liv. 8, 3 ss. Si bien su número fue durante los primeros tiempos de la República de 900 hombres (15 manípulos o 30 centurias de 30 hombres), posteriormente pasaron a estar compuestos por 1.200 soldados (10 manípulos o 20 centurias de 60 hombres), antes de las reformas realizadas por Mario. Livio cita a estos principes frecuentemente. Por poner sólo algunos ejemplos: 7, 23, $7 ; 7,34,5 ; 9,35,6 ; 30,8,5 ; 30,32,11 ; 30,34,10$.

23. Liv. $3,17,8$, en referencia a P. Valerio Publícola.

24. Liv. 6, 18, 3 respecto a los plebeyos más cercanos a Marco Manlio, que encabeza el movimiento de oposición contra los patricios a causa de las deudas a principios del s. IV a. C.

25. Liv. 26, 32, 1-2, en este caso en referencia a la intervención de T. Manlio Torcuato en la acusación a Marco Claudio Marcelo por parte de los sicilianos. que se casó con la hija de Tarquinio el Soberbio por ser longe princeps Latini $(1,49,9)$; Ato Tulio, definido como el primero entre los volscos (princeps Volsci: 2, 35, 7): Graco Clelio, el más destacado entre los ecuos (princeps in Aequis erat: 3, 25, 5); Atio Clausio, principem nobilitati vestrae (i. e. de los sabinos: 10, 8, 6); el iacetano Amusico (princeps eorum: 21, 61, 11); Numerio Decimio, princeps de la ciudad de Boviano y de todo el Samnio (22, 24, 11-12); Decio Magio, el ciudadano más destacado de Capua $(23,10,10)^{26}$; Dorímaco, princeps de los etolios $(26,24,7)^{27}$; Eneas, princeps Aetolorum $(32,32,11)$; Timón, princeps de la ciudad de Tebas $(33,5,1)$; el propio Aníbal, que tras su huída a la búsqueda del amparo de Antíoco es calificado como princeps civitatis $(33,48,10)$; Euríloco, el principal de los magnetes $(35,31,6$ y 36, 33, 6) 28 ; Filopemén, el líder de los aqueos (Achaeorum principem: 35, 47, 4) ${ }^{29}$; Pausanias, princeps civitatis de los fereos (36, 9, 5); Mnasíloco, princeps Acarnanum $(36,11,8)^{30}$; Herodico, un dirigente salio (principem Thessalorum: 40, 4, 2); Póride, la persona más destacada del pueblo de los enianes (longe principi gentis Aenianum: 40, 4, 4); Eupólemo, el hombre más destacado de Hípata y estrategos de la misma $(41,25,4$ y 6, 5); Praxo, principem auctoritate et opibus Delphorum (42, 15,

26. Sin embargo, según el propio Livio, no ejerció el más destacado de los honores de su comunidad por la falta de sentido común de sus conciudadanos (Liv. 23, 7, 4), aunque debía ser miembro del senado (Liv. 23, 10, 3 ss.).

27. Cfr. Pol. 4, 3, 5 ss.; 13, 1; 18, 54, 4. Sabemos que este personaje fue enviado por la Liga Etolia para vigilar los asuntos del Peloponeso, región que invadió en 220 a. C. junto a Escopas. Un año después fue nombrado strategos de la Liga. En 211 a. C. se encargó, junto a otros destacados personajes etolios, de firmar un tratado de alianza con los romanos y, años más tarde, es nombrado legislador de la Liga. Finalmente, en 196 a. C. fue enviado a firmar un tratado de paz y alianza con Ptolomeo V.

28. Cfr. Pol. 5, 63, 12; 65, 2; 79, 10 y Liv. 35, 32, 1; 34, 6 ss.; 37,5 . En estos pasajes encontramos al personaje al frente de fuerzas militares en el contexto de la alianza de Antíoco y Ptolomeo. Además, tras el pasaje en el que Livio presenta al personaje como uno de los principales de la ciudad, el mismo Livio nos informa de que era magnetarca, el magistrado de mayor rango de su comunidad (Liv. 35, 31, 11; 39, 6; y 43, 5).

29. Personaje muy destacado en la obra de Polibio y citado por el historiador en numerosas ocasiones jugando un papel muy relevante. Polibio, que elogia al personaje de quien escribió una obra monográfica hoy perdida, destaca de él tanto sus dotes militares, como su habilidad política. Cfr., especialmente, Pol. 10, 21-24 o Plut. Phil., así como las numerosas citas del personaje en el propio Livio (libros 31 a 39) o Juniano Justino (libros 30 a 34). Gracias al primero sabemos que era de noble linaje y que descendía de los hombres más ilustres de Arcadia. Entre otros honores, fue hiparco y estrategos de la Liga Aquea en ocho ocasiones.

30. Cfr. Pol. 21, 17, 7 y 43, 11 y Liv. 36, 12, 4-5 ss. (aparece formando parte de una embajada); 37, 45, 17; y 38, 38, 18 (con exigencias para que fuera entregado como rehén). 
3); Pantaleón, Aetoliae princeps $(42,15,8)^{31}$; Ramio, princeps Brundisi $(42,17,3)^{32}$; Arquidamo, principem Aetolorum (43, 21, 8 y 22, 3) ${ }^{33}$; Monuno, Dardanorum principis $(44,30,4)^{34}$; o Cefalón, de Tecmón $(45,26$, 10).

No cabe ninguna duda de que, al menos para Tito Livio o para las fuentes que éste consultó, tales personajes contaban entre los más destacados dentro de sus comunidades. Esta afirmación está fuera de dudas cuando el historiador usa expresiones superlativas como longe princeps Latini o longe principi gentis Aenianum, refiriéndose a Octavio Mamilio Tusculano y a Póride, respectivamente. Sin embargo, es posible, tanto por el repetitivo uso de la fórmula, como por la ausencia de expresiones superlativas como las que acabamos de ejemplificar, que puedan albergarse algunas dudas cuando el patavino usa simplemente el concepto princeps para calificar a alguno de estos personajes, quienes, sin embargo, debieron contar con seguridad entre las personalidades más relevantes de una determinada comunidad humana en cada uno de los contextos históricos en los que están enmarcados.

Por otra parte, en un número significativo de casos, Livio destaca a dos personajes dentro de una comunidad. Así, por ejemplo, Carilao y Ninfio, son destacados como los principes de Palépolis (principes civitatis: 8 , 25, 9); Hannón, que encabezaba a la facción opositora a los Barca en Cartago $(21,3,3)^{35}$; Dasio y Blatio, principes de la ciudad de Salapia $(26,38,6)$; Indíbil y Mandonio, omnis Hispaniae principibus $(27,17,3)$; Corbis y Orsua, los principales que se disputaban la primacía de la ciudad de Ibe tras la muerte del padre de éste, también principal de la comunidad $(28,21,6$ y

31. Cfr. Pol. 20, 9, 1 y 28, 4, 8-9.

32. El hecho de que el personaje hospitioque et duces Romanos omnes et legatos, exterarum quoque gentium insignis, praecipue regios muestra el rango del mismo en su comunidad. Cfr. también Liv. 42, 41, 4.

33. Aunque en el primer testimonio la traducción es «un jefe etolio»; en el segundo se dice que los principales llamaron al rey por la autoridad de Arquidamo. En este caso el personaje parece ser realmente uno de los personajes más destacados, como lo demuestra que fuera general en jefe de la Liga Etolia en tres ocasiones entre los años 191 y 181 a. C. Cfr. también Pol. 18, 21, 5; 20, 9, 2; 28, 4, 8 y Liv. 43, 22, 11 (Arquidamo gozaba de gran popularidad e influencia en Aperancia) y 44, 43, 6 .

34. Este testimonio es llamativo en el sentido de que se traduzca como rey de los dárdanos, a pesar de que el texto en latín no lo cita como rex, sino como princeps. En cualquier caso, el concepto de rex parece aludir a cierta supremacía supralocal o regional y, en muchas ocasiones se vincula al liderazgo de fuerzas militares en el contexto de una symmachía: Vide E. Sánchez Moreno (2019: 84), A. Pérez Rubio (2019: 180 s.) y E. García Riaza (2019, 226-228), quien además acertadamente recuerda que este título podía ser consecuencia de la ratificación u oficialización oficial romana de un liderazgo indígena preexistente.

35. Entendemos que, del pasaje, subyace que los principales cartagineses serían Hannón y, en este caso, Asdrúbal Barca.
7); Eversa y Calícrito, principes civitatis en Tebas (42, 13, 7); Dinón y Poliarato, principales de Rodas (44, 23, 10); Teutico y Bello, principales entre los ilirios $(44,31,9)^{36}$; Antínoo y Teódoto, principales de Pasarón $(45,26,5)$.

Cabría preguntarse las razones por las que Tito Livio enumera a sendas parejas de personajes como los más relevantes, generalmente de sus respectivas ciudades. ¿Se trata de sistemas que podríamos asimilar a diarquías? ¿De magistrados colegiados? ¿De sistemas bicefálicos en los que dos personajes se reparten distintas competencias? El testimonio de Carilao y Ninfio, dentro del contexto de la II Guerra Samnítica (327-304 a. C.), nos relata cómo estos dos personajes pergeñan la rendición frente a Roma. Carilao negocia con el cónsul Q. Publilio Filón y parece actuar en representación pública (publice petere) recibiendo tres mil soldados romanos, que parece capitanear junto al tribuno Lucio Quincio, para introducirse en la ciudad. Por su parte, Hannón y Asdrúbal parecen ser las personalidades más relevantes dentro de dos corrientes de opinión en Cartago: los que deseaban una confrontación con Roma y los que preferían atender a la paz para desarrollar los intereses comerciales de la ciudad en el Mediterráneo Occidental. De nuevo Dasio y Blatio ejemplifican dos corrientes de opinión en la ciudad de Salapia: permanecer al lado de Aníbal o favorecer la causa de Roma. Además, Livio afirma que ambos personajes eran rivales por el poder en la ciudad y que Blatio propone a Dasio la entrega de la misma a los romanos. En cuanto a Indíbil y Mandonio, se ha especulado con la posibilidad de que se tratase de los representantes de un régimen bicefálico, si bien es más probable que Indíbil actuara como rey de los ilergetes y su hermano Mandonio fuera uno de los consejeros, posiblemente, dados los lazos de sangre, el de mayor importancia ${ }^{37}$. En el caso de Corbis y Orsua, parece fuera de dudas según el testimonio de Livio que, tras la muerte del padre de Orsua, que detentaba hasta ese momento el poder en la ciudad, el combate que protagonizaron ante Escipión tenía como objeto resolver con las armas la primacía de su comunidad. De Eversa y Calícrato solo

36. En los pasajes anteriores aparece Gencio como rey ilirio y ante su derrota frente a los romanos manda a estos dos personajes al pretor para parlamentar. Aquí los principales actúan como principes gentis, no como miembros de un senado u órgano colegiado. Es posible que Gencio fuera el máximo representante de los ilirios y los otros dos personajes de algunas de las ciudades aliadas. Sobre el rey de los ilirios, véase D. Džino (2010: esp. 55 ss.).

37. Cfr. al respecto P. Moret (2002-2003: 26-28), quien apunta que Polibio y Livio no presentan a los dos personajes con los mismos matices y que este último modificó voluntariamente el personaje de Mandonio para privilegiar la composición literaria y el dramatismo en detrimento de la exactitud histórica. Sobre ambos hermanos, véase Pol. 3, 76, 7; 9, 11, 3-4; $10,18,7 ; 10,35,6 ; 10,37,2-9 ; 10,40,3$ y $10 ; 11,26,6 ; 11$, $29,3-5 ; 11,31,1$ у $4 ; 11,33,6 ; 21,11,7$. 
podemos decir que debían ostentar una posición destacada en Tebas, puesto que eran los delegados que se dirigieron al synedrion de la confederación beocia en contra de la alianza con Perseo en el contexto previo a la III Guerra Macedónica ${ }^{38}$. Dinón y Poliarato eran los principales representantes de la facción antirromana en Rodas, donde eran miembros de su Consejo ${ }^{39}$. Teutico y Belo, calificados como principes gentis, son enviados por el rey de los ilirios Gencio, aliado de Perseo contra los romanos, para solicitar una tregua al pretor romano. Finalmente, Antínoo y Teódoto, principes civitatis y praepotentis viros, aparecen como defensores de la facción antirromana y apoyando la alianza con Perseo en su ciudad, ordenando cerrar las puertas de la misma ante el ataque de los romanos ${ }^{40}$.

De los ejemplos expuestos supra, no podemos, por lo tanto, deducir que se trate de personajes que ostentaban una capacidad decisoria especial -excepción hecha, con los matices expuestos, de Indíbil y Mandonio-, sino que, en los contextos analizados, Tito Livio suele emparejar a estos principes para representar corrientes de opinión a favor o en contra de Roma, generalmente otorgando valores negativos a aquellos que representaban una posición desfavorable a los intereses de los romanos. Sin embargo, no cabe duda de que todos los personajes que hemos analizado jugaban un papel relevante en sus respectivas comunidades y tenían una posición que les permitía influir en la opinión de su entorno social y, especialmente, de las oligarquías, que tenían la decisión última sobre la conveniencia o no de una alianza con Roma. Además, cuando acudimos a otros historiadores, esencialmente Polibio que, no lo olvidemos, fue utilizado como fuente principal por Tito Livio sobre todo para los asuntos concernientes a Grecia y Oriente, reparamos en el hecho de que la importancia otorgada por el patavino a algunos personajes está muy por debajo del papel que debieron jugar éstos en los hechos narrados ${ }^{41}$. Quizás el mejor ejemplo de lo que decimos sea el aqueo Filopemén, al que Livio no resta importancia pero cuya figura queda

38. Sabemos por Polibio $(22,4,8)$ que Calícrato fue enviado a Roma como embajador representando a los beocios. Es probable, aunque nada sabemos por las fuentes, que ambos personajes hubieran desempeñado puestos de responsabilidad en Tebas.

39. Cfr. Polibio 27, 7, de donde se deduce que ambos, pese al perfil negativo que de ellos hace el megalopolitano, debían ser personajes con cierta influencia en la población, como también se deduce de su intervención en la asamblea: 29,11 , 3. Sobre los mismos véase también Pol. 27, 14, 2; 28, 2, 3 y 18,$14 ; 30,6,1 ; 30,7,10 ; 30,8,2$ y $7-8 ; 30,9$.

40. Cfr. Polibio: Antínoo 27, 15, 7 y 30, 7, 2; y Teódoto 27, 16, 1 y $30,7,2$. En el primero de estos pasajes se significa que Antínoo, junto a otro personaje llamado Céfalo, gozaban del favor popular y «gobernaban el estado según sus principios».

41. Sobre las estrategias de la diplomacia romana en Grecia y su papel en la mediación y arbitraje de conflictos véase E. S. Gruen (1984: 13-201) que enfatiza la adaptación y originalidad de las mismas respecto a la experiencia acumulada empequeñecida en la obra del historiador romano si la comparamos con la de Polibio o Plutarco, entre otras fuentes. Es muy posible que esta característica se deba a la visión «romanocentrista» que destila Livio en su obra, quien seguramente no estaba interesado en elogiar a estos personajes, ni en detenerse a destacar sus virtudes, carreras o cualidades tal y como lo hace con los romanos que jugaron un papel esencial en los hechos que nos narra.

Por otra parte, como acabamos de adelantar brevemente, Tito Livio usa el concepto de princeps/principes profusamente para hacer referencia a personajes de relevancia dentro de una comunidad o cualquier otra organización social que estuvieron a favor o en contra de los intereses romanos, en general, siempre dentro del contexto de expansionismo de la Urbs por el Mediterráneo ${ }^{42}$. Un buen ejemplo al respecto es el papel desempeñado por los principes siracusanos en la II Guerra Púnica ${ }^{43}$. Hierón II mantuvo desde el primer conflicto contra Cartago una alianza con los romanos que llevó a la ciudad a convertirse en la más destacada dentro de Sicilia, extendiendo su influencia, al menos, a la parte más occidental de la isla y asegurando la estabilidad del gobierno del tirano durante décadas ${ }^{44}$. Sin embargo, como nos narra el propio Livio $(24,4$ ss.), dicha alianza se resquebrajó con la muerte de Hierón en el año 215 a. C. pues su nieto, Jerónimo, que contaba por entonces con tan solo quince años, debía sucederle en el gobierno. Ante esta situación, se nombró quince tutores para el joven rey, pero finalmente Adranodoro y Zoipo, a la sazón tíos políticos de Jerónimo, junto con Trasón lograron convertirse en las figuras políticas más influyentes de Siracusa. Con el estallido de la II Guerra Púnica, se había conformado un partido filopúnico y otro filorromano en la ciudad, siendo Adranodoro y Zopio defensores de la primera corriente y Trasón de mantener la alianza con los romanos. Sin embargo este último fue acusado de conspirar contra el joven rey y acabó siendo torturado. Ante esta situación, Aníbal mandó emisarios para sellar la alianza con los siracusanos y Apio Claudio, pretor en la isla, envió una embajada para conocer las intenciones de Jerónimo, quien despachó a la misma prácticamente

anteriormente en las relaciones de Roma con los pueblos itálicos y mediterráneos dentro del marco expansionista de la Urbs.

42. Sin lugar a dudas Livio utiliza de forma muy asidua el concepto que estamos analizando dentro de este contexto que, junto a las relaciones diplomáticas que analizaremos infra, supone la mayor parte de los testimonios que hemos recogido para la realización de este estudio. Dada la cantidad de pasajes recopilados en ambos apartados y la imposibilidad de analizarlos de forma individualizada, nos limitaremos a citar algunos ejemplos ilustrativos al respecto.

43. Sobre Livio y la II Guerra Púnica, véase D. S. Levene (2010).

44. Al respecto de la situación de Sicilia previa al dominio romano, véase J. Dubouloz y S. Pittia (2009: 85 ss.). 
entre burlas ${ }^{45}$. Sin extendernos mucho más en el asunto, diremos que el rey fue asesinado y que en Sicilia estuvo a punto de estallar una guerra entre las dos facciones, cuyo principal episodio se escenificó en Siracusa. En este contexto, uno de los principes, de nombre Polieno, realizó un discurso ante la asamblea conminando a los siracusanos a no ser partícipes de una guerra civil (24, 22, 1-4). Los enfrentamientos entre ambas facciones en la ciudad continuaron, siendo aquí cuando encontramos el discurso ante la asamblea de otro de los principes siracusanos, Apolónides, apelando a la unidad de opinión de sus conciudadanos por el bien de la ciudad $(24,28)$, aunque, sin embargo, era más partidario de mantener la tradicional alianza con los romanos (24, $28,6)^{46}$. No obstante la ciudad permaneció bajo control filopúnico, encabezada por Epicides y otros principales, lo que no es óbice para que los defensores de pactar con los romanos, muchos de ellos aristócratas, continuaran intentando que la ciudad cayera en manos de Marcelo, como sabemos por el propio Livio $(25,23)$. De hecho, los miembros de la delegación que se entrevistaron con Marcelo justo antes de la caída completa de Siracusa-algunos de ellos elegidos como pretores, $i$. $e$. arcontes-se declaraban ellos mismos filorromanos y se lamentaban de su situación desde la llegada al poder de Jerónimo ${ }^{47}(25,29,1$ ss.).

Otro buen ejemplo del papel que jugaron los principes como representantes de las filias y fobias que despertaban los romanos en un contexto cada vez mayor de expansionismo e intervencionismo de la $U r b s$ en distintas regiones del Mediterráneo, lo podemos encontrar en Grecia en el contexto de la II Guerra Macedónica ${ }^{48}$. En efecto, tanto en las diferentes

45. Como puso de manifiesto E. García Riaza (2013: 388), existe una interrelación entre disensiones internas y actuaciones oportunistas, en este caso, púnicas, siendo posible que cartagineses y romanos estuvieran en muchas ocasiones en el origen de esas disensiones, pese a que frecuentemente sea difícil de contrastar en las fuentes existentes. Por otra parte, fue frecuente entre los romanos utilizar la diplomacia para comprobar y reafirmar lealtades y alianzas. Cfr. al respecto $\mathrm{E}$. García Riaza (2016: 243-261), que analiza varios testimonios al respecto dentro del contexto de la II Guerra Púnica en la península Ibérica.

46. En este caso Apolónides abrió un encendido debate que concluyó con la decisión de enviar una embajada para firmar los términos de la paz con los romanos $(24,28,9)$.

47. Sobre la figura de Jerónimo en Livio y sus similitudes y diferencias en Polibio, vide D. S. Levene (2010: 155-157).

48. Para A. M. Eckstein (2006: esp. 116 s.) los distintos estados del Mediterráneo oriental helenístico vivían en un contexto de competitividad, violencia y guerra que se había convertido en un problema sistémico. Una diplomacia primitiva, la falta de compromiso entre los estados en conflicto y la ausencia de un derecho internacional -como factores estructurales-, así como el colapso de Egipto y la creciente interrelación entre los eventos políticos del Mediterráneo Oriental y Occidental, facilitaron y propiciaron la intervención de Roma. Esta se explica, además, por la llegada de numerosas embajadas griegas solicitando ayuda contra Filipo V y Antíoco III que, confederaciones griegas, como, dentro de ellas, cada una de las ciudades que componían dichas alianzas, existieron notables divisiones, en este caso, entre los partidarios filomacedónicos y los filorromanos. Así, por ejemplo, es notoria la stasis interna que se vivió en la confederación beocia que, precisamente, provocó la intervención romana en los asuntos internos del koinon y, a su vez, muy probablemente, la radicalización de las posturas de los defensores de una y otra tendencia $^{49}$. En este sentido, poco después de la batalla de Cinoscéfalas (junio de 197 a. C.), Bráquiles ${ }^{50}$, de clara filiación promacedónica -principem fautorum regis, según Livio: 33, 28, 1-, fue elegido beotarco de la confederación (Pol. 18, 43, 3). Sin embargo, los líderes de la facción prorromana Pisístrato y Zeuxipo, calificado como principem gentis $(33,29,1)$, se pusieron en contacto con el cónsul T. Quinctio Flaminino para asesinar, como así ocurrió, a Bráquiles ${ }^{51}$. Dicha división entre los beocios reapareció con fuerza en los albores de la III Guerra Macedónica, cuando la confederación beocia firmó una alianza con Perseo. Como el propio Livio reconoce $(42,30,1-7)$, la mayor parte de la población estaba a favor de esta alianza y entre la oligarquía se podían reconocer distintas tendencias: los prorromanos, los promacedonios y un tercer grupo que era partidario de la paz pero que, en caso de tener que elegir, preferían estar sometidos a Roma. Uno de los principes de la confederación, Ismenias -elegido estrategos en 171 a. C.- era representante de la facción promacedonia (principem alterius partis; Liv. $42,38,5)^{52}$. Las disensiones se muestran en que unos exiliados beocios se presentaron ante Q. Marcio Filipo en Tesalia para informar a los romanos de que la responsabilidad de la alianza con Perseo era de Ismenias, asegurando que no

ante el aumento de poder de sus respectivos reinos, animaron al senado a tomar el conflicto como una guerra preventiva frente al peligro de las consecuencias que podían suponer los cambios del statu quo en Oriente. Vide A. M. Eckstein (2008: esp. 268-270; 2009: 97 s.)

49. Sobre el tema, véase J. Pascual (2011: esp. 244 ss.) y F. J. Gómez Espelosín (1995: 127-144), que analiza asimismo los antecedentes y causas de la alianza de los beocios con Filipo V.

50. Bráquiles era hijo de Neón y nieto de Ascondas, ambos filomacedonios (Pol. 20, 5, 6). Nuestro personaje ya acompañó a Filipo $\mathrm{V}$ a la fallida conferencia de Lócride en noviembre de 198 a. C. (Pol. 18, 1, 1-3) y fue epistátês de Esparta, gozando del favor de Filipo y de Antígono (Pol. 20, 5, 12-13).

51. Cfr. Pol. 18, 43, 5-12 y 20, 7, 3. Aunque Flaminino no participó directamente en el asesinato, sí sabemos, gracias a Polibio, que era conocedor de los hechos. Sobre Zeuxipo, que debió jugar el papel primordial en la conjura, cfr. Pol. 18, 43, 5-12 (planes de asesinato de Bráquiles); 22, 4, 4 ss. Sobre Pisístrato: Pol. 18, 43, 5.

52. Los principales representantes de esta facción en los últimos años de la confederación fueron Neón, hijo de Bráquiles; Hipias, arconte federal en 172; Dícetas; e Ismenias (cfr. J. Pascual, 2011: 245). Sobre estos personajes, véase Pol. 27, $1-2$. 
todas las ciudades de la confederación eran partidarias de la adopción de esta postura (Liv. 42, 38, 2-5). De hecho, Eversas y Calícrato, de la facción prorromana, hablaron en el synedrion en contra de la alianza con Perseo y fueron asesinados, probablemente por mandato del rey macedonio, cuando se dirigían a Roma a denunciar la situación.

Como ya anunciamos anteriormente, estos son solo dos ejemplos de los muchos que existen en la obra de Livio, trufada de luchas internas intestinas entre filorromanos y sus enemigos; o que nos cuentan defecciones o cambios de bando, tanto a favor, como en contra de Roma. Es imposible analizar con profundidad todos los testimonios, aunque sí citar brevemente algunos ejemplos más: dentro del contexto de la II Guerra Samnita, el desencuentro entre la aristocracia de la ciudad de Sátrico, una parte de la cual era partidaria de separarse de la alianza con Roma y otra de permanecer fiel a la misma $(9,16,6)$; o del desertor de Sora, favorable a la alianza con Roma, que llamaba a la defensa de la ciudad ante las casas de los ciudadanos principales $(9,24,10)$; los jóvenes príncipes de las ciudades de Ausona, Minturnas y Vescia que se conjuraron para entregar sus ciudades a Roma frente a la defección de las mismas a favor de los samnitas $(9,25,4)$; o las conjuras de los principes de Capua contra los romanos $(9,26,5)$. También dentro de este contexto podemos clasificar el testimonio sobre la situación en Cartago en los prolegómenos de la II Guerra Púnica. En efecto, si los Barca eran partidarios del conflicto con Roma, existía una parte de la oligarquía, representada por Hannón, que era más favorable de proteger los intereses comerciales de la metrópoli extendiendo su influencia hacia occidente para no entrar en conflicto con la zona de influencia romana en el Mediterráneo $(21,2,5)$; o de la carta que envió Aníbal a sus partidarios en Cartago -en el contexto del cerco a Sagunto- para frenar las posibles concesiones que pudieran hacer los partidarios de la facción de Hannón a los romanos $(21,9,4)$.

Como podemos apreciar por el análisis de los ejemplos expuestos, los principes de distintas ciudades o incluso de organizaciones supralocales jugaron un rol decisivo en el proceso de conquistas romanas por el Mediterráneo, ya fuera por su oposición al control y el intervencionismo de la ciudad lacial, ya sea por su apoyo que, a la postre, resultaría decisivo en el éxito del expansionismo de la Urbs. Obviamente, no podemos minusvalorar los frecuentes traspiés diplomáticos o incluso militares en el proceso de conquista del Mediterráneo por parte de Roma, pero, igualmente, sería poco objetivo negar la habilidad de los romanos para generar, inflamar o incluso apoyar abiertamente disensiones internas con las diferentes comunidades con las que tuvo contacto. Si analizamos dicho proceso desde el punto de vista de la población peregrina, tales disensiones obedecieron con seguridad a la defensa de los intereses de las oligarquías $-\mathrm{y}$, en mucha menor medida, de la población a la que representaban-, divididas entre quienes creían que lo mejor era aliarse y/o aceptar la influencia romana en sus comunidades, frente a los que estimaban que lo mejor era defender su independencia frente al cada vez mayor intervencionismo de Roma ${ }^{53}$. Un testimonio ejemplar y explícito de estas disensiones y de los objetivos que había dentro de cada uno de los grupos de opinión dentro de una comunidad nos lo ofrece el propio Livio $(45,31,4)$. Nos situamos en el contexto del proconsulado de L. Emilio Paulo en Grecia, quien tras haber derrotado a Perseo en la batalla de Pidna (168 a. C.), había permanecido allí para terminar de poner orden, especialmente, en los asuntos de Macedonia. En lo que más nos interesa aquí, Livio expone que en las ciudades existían tres grupos de principales (tria genera principum in civitatibus erant): dos que apoyaban al poder romano -quienes, además, acaparaban las magistraturas y las embajadas-o a los reyes, respectivamente, y que habían ganado influencia para sus intereses particulares a base de oprimir a la ciudadanía y un grupo intermedio que era el único en defender la libertad y las leyes. Además, la facción prorromana se dedicaba a denunciar a los defensores de Perseo para que fueran perseguidos y llevados ante la justicia, con lo que se eliminarían a sus principales rivales haciéndose con el control de las ciudades o de ciertas regiones en Grecia. Este testimonio muestra perfectamente las divisiones internas de las ciudades de Grecia, a favor de Roma o de Perseo, así como el objetivo de las oligarquías de defender sus propios intereses frente a los de la comunidad a la que representaban ${ }^{54}$. Finalmente, muestra a las claras las ventajas de haber elegido el bando ganador y las depuraciones a las que tuvieron que hacer frente los partidarios de la opción que resultó vencida, proceso este que se debió repetir en la evolución del expansionismo romano y que, junto a los procesos de emigración itálica, fundación de colonias, etc. debió suponer una reconfiguración profunda de las oligarquías locales por todo el Mediterráneo.

Como ya anunciamos con anterioridad, uno de los contextos en los que los principes tienen un papel de relevancia en la obra de Tito Livio es en el de las relaciones diplomáticas que las comunidades mantuvieron con Roma en el proceso de expansión, tanto por la península Itálica como por el Mediterráneo, de la ciudad lacial. De hecho esta serie de testimonios es enormemente prolija en la obra del historiador patavino

53. De hecho, esta dicotomía seguirá estando presente en el pensamiento de muchos intelectuales griegos. Así, por ejemplo, pensemos en Plutarco o Dión Crisóstomo quienes, más de dos siglos después de que el mundo helenístico comenzara a caer bajo el dominio romano, seguían criticando la división existente en las ciudades y entre sus élites frente al intervencionismo, en especial, de los gobernadores romanos. Sobre el tema, véase M. López Salvà (1990-1991: 25-36) o V. Marotta (2005: 135 ss.).

54. En efecto, son numerosas las ocasiones en las que, al menos según Livio, los intereses de ciertos grupos dentro de la oligarquía, no coincidían con la de la mayoría de los ciudadanos de una determinada comunidad. Cfr., por ejemplo, 42, 30, 1. 
$y$, en muchas ocasiones, se entremezcla con el apartado que hemos analizado anteriormente, es decir, el de la narración de disensiones internas entre las oligarquías que veían con buenos ojos prestar apoyo a los romanos frente a aquellos que, por distintas razones, eran defensores de mantener la autonomía ${ }^{55}$

Dentro de este apartado, podemos distinguir a principes participando en distintas asambleas o convocatorias con el objetivo de negociar y/o sellar alianzas para hacer frente al expansionismo romano. Este sería el caso del encuentro que mantuvieron los principales representantes de las ciudades etrurias en el contexto de la primera campaña contra Veyes $(2,44,8)$; de los jefes de Veyes y Fidenas que discuten cuál sería el mejor centro de operaciones en su alianza contra los romanos (4, 31, 8; 437 a. C.); de los principes etruscos ex omnibus populis reunidos en el templo de Voltumna para preparar una campaña contra Roma $(6,2,2 ; 389$ a. C.); de los latinos que preparaban una campaña contra Roma (8, 3, 2; 341 a. C.); de los principes etruscos que eran recriminados por sus conciudadanos por no haber convencido a los galos para que entraran en conflicto contra los romanos $(10,13,3)$; o de los samnitas que, derrotados por los romanos, solicitan a los etruscos una asamblea para convencerlos de declarar la guerra contra los romanos $(10,16,3)$. También dentro de este contexto, pero fuera del escenario itálico y ciñéndonos exclusivamente al contexto de la II Guerra Púnica, podemos incluir las alianzas que estableció Asdrúbal con principes hispanos en la preparación del conflicto abierto contra Roma $(21,2,5)$; o las establecidas por Aníbal con los principes galos -a cambio de oro-para que rechazaran ayudar a los romanos que tenían el objetivo de impedir el paso del ejército cartaginés por los Alpes $(21,20,8)$; de la supuesta alianza ofrecida a Aníbal por principes de algunos pueblos de los Alpes, que finalmente derivó en una emboscada contra el ejército cartaginés $(21,34,2)$; de la incitación a la defección que realizaron los cartagineses frente a los galos en la preparación de la batalla del Tesino $(21,45,3)$; de los tres jinetes campanos liberados por Aníbal, al que le aseguran que Capua sería una presa fácil para el ejército cartaginés y que le prometen regresar con muchos de los principes más sobresalientes de su ciudad $(22,13$, 4) ${ }^{56}$; o de Pacuvio Calavio, el campano que se reunió con Aníbal para confirmar la alianza de la región con el cartaginés y traicionar la alianza con Roma $(23,8,3)$.

55. De nuevo, recordemos que el volumen de testimonios que nos ha transmitido Livio al respecto es inabarcable para realizar un análisis detallado de cada uno de ellos en el presente trabajo, por lo que nos limitaremos a detallar algunos ejemplos de los mismos.

56. No obstante, en dicho contexto no está claro si se trata de confirmar una alianza con Aníbal mediante los personajes más destacados de la comunidad o de si Aníbal pidió como garantía que esos jinetes regresaran con elementos cualificados de la ciudad para confirmar las intenciones reales de los mismos.
Hay también algunos testimonios que hacen referencia a la llamada a consultas a Roma para explicar la posición de los que se suponía que eran aliados de la Urbs. En este sentido, las autoridades romanas usaron esta herramienta preventiva para aclarar la posición real de ciertas comunidades frente a Roma ${ }^{57}$. Así, por ejemplo, el senado llamó a los principes de la colonia de Ancio, sobre la que recaían sospechas de haberse aliado con los ecuos, a los que Roma finalmente acabó enfrentándose (3, 4, 5; 464 a. C.); en 340 a. C. Roma convoca a diez jefes latinos, puesto que éstos preparaban una campaña contra la $\operatorname{Urbs}(8,3,8)^{58}$; o los notables de Capua que fueron llamados a Roma para dar explicaciones ante una posible conjura favorable a los samnitas $(9,25,3)$.

Otros testimonios dan fe de la utilización de la diplomacia para evitar la toma mediante las armas de una determinada plaza - con distinta suerte según los casos-, en muchas ocasiones previa intimidación mediante la toma de posiciones de las fuerzas militares romanas en las cercanías de una ciudad. Este es el caso de los emisarios que mandó L. Emilio Régilo para sondear las intenciones de los principes y magistrados de Pátara $(37,17,4)$ o de Focea $(37,32,1)$.

Tampoco son extrañas las referencias de Livio a legaciones o embajadas que son enviadas a Roma o a parlamentar con los representantes del poder romano en territorio extraitálico -fundamentalmente cónsules y pretores- para solicitar la ayuda de Roma o, en caso de derrota, para negociar las condiciones de la deditio in fidem, ya sea en primera instancia con el magistrado romano al cargo de una campaña militar o, en un segundo momento, enviando representantes al senado ${ }^{59}$. En este sentido, podemos recordar entre otros a los ciudadanos y principes sutrinos que solicitaron la ayuda del dictador M. Furio Camilo ante el sitio impuesto a su ciudad por los etruscos $(6,3,4$; 389 a. C. ); los representantes de la embajada de los campanos que solicitan ayuda a Roma ante el ataque de los samnitas (7, 31, 3; 343 a. C.); de los principes celtíberos que acuden en legación a Escipión junto con rehenes y que, posteriormente, toman las armas frente a los cartagineses (22,

57. Estrategia que fue utilizada con relativa frecuencia por los romanos durante el proceso de expansión por el Mediterráneo. Sobre este particular véase E. García Riaza (2016: 243-261), con análisis de los principales testimonios referidos a Hispania y Galia, atendiendo en este último caso al corpus cesariano.

58. Entre ellos destacaban los dos pretores de la Liga Latina: L. Annio Setino y L. Numisio Circeyense.

59. Sobre el tema véase A.-M. Sanz (2015: 87-105). La diferente visión de los magistrados y el senado en estas negociaciones llegaron a originar tensiones entre ambas instancias. A partir de la primera mitad del s. II a. C. el senado parece reafirmar sus competencias diplomáticas frente a la libertad de la que habrían disfrutado los magistrados en periodos anteriores, a los que se les permitió mayor margen de maniobra. Cfr. también J. Edmondson (2014: esp. 29 ss.), con comentario de diferentes visiones historiográficas al respecto. 
21, 7). Como podemos comprobar, los miembros de estas embajadas son calificados en numerosas ocasiones como principes de forma genérica, pero también existen otros muchos pasajes en los que Livio señala a un miembro en concreto de la legación como el más destacado, por su posición social, elocuencia o por tomar la iniciativa, dentro de una embajada ${ }^{60}$. Este sería el caso, por poner solo algunos ejemplos, de los megalopolitanos Diófanes y Licortas, representantes de una delegación aquea que acudieron a Roma tras fracasar la mediación del cónsul en Grecia entre la Liga y los lacedemonios $(38,32,6)$; o de Apolonio, embajador del rey Antíoco enviado ante el senado de Roma para disculparse de la entrega tardía de los tributos $(42,6,6)$; o de Sátiro, jefe de una embajada rodia enviado a Roma ante las posibles acusaciones que Éumenes pudiera haber vertido al respecto de la alianza de su ciudad con Perseo $(42,14,6)$; o de Micitión, principal de una embajada de los calcidenses que causó una viva impresión entre los romanos por estar impedido de las piernas y entrar a la recepción en litera $(43,7,5)$; o del anónimo princeps legationis de los rodios enviado a $\operatorname{Roma}(44,15,2)$. Como ya hemos adelantado, debemos suponer que los embajadores destacados por Livio en cada uno de los ejemplos expuestos, debían tener un estatus destacado dentro de sus comunidades o destacaron por determinadas cualidades ${ }^{61}$. De hecho en ciertas ocasiones el historiador patavino ofrece datos explícitos al respecto, como por ejemplo sería el caso de Antipatro, cabeza de una delegación del Imperio seleúcida enviada a Roma para confirmar las condiciones de paz negociadas con L. Cornelio Escipión Asiático y del que sabemos que era sobrino del rey Antíoco III $(37,55,3)$.

Al contrario, también encontramos a representantes romanos enviados a reunirse para negociar con los principes de otros pueblos o comunidades con la finalidad de respetar o, en otros casos, de comenzar una alianza con Roma. Dicha postura es relativamente frecuente en la diplomacia romana, en especial en contextos históricos en los que la Urbs vio realmente en peligro sus intereses y prefirió intentar establecer alianzas ante un previsible conflicto abierto con enemigos potencialmente peligrosos y/o, como decimos, en momentos de extremada debilidad de la ciudad lacial ${ }^{62}$. Este es el

60. Aunque la mayoría de los testimonios que podemos clasificar en este grupo hacen referencias a miembros destacados de las embajadas por sus cualidades positivas, también existen principes legationis que aparecen con connotaciones negativas, como por ejemplo Hárpalo, enviado por Perseo para presentar excusas y justificaciones ante los romanos y del que se destaca su autosuficiencia desmedida $(42,14,3)$.

61. Sobre las mismas, véase J. F. Rodríguez Neila (2010: esp. p. 35).

62. Como ya pusieron de relevancia algunos investigadores desde hace décadas, la vía diplomática fue enormemente importante en el contexto del expansionismo romano hasta tal extremo que es imposible tener una comprensión cabal y completa de este fenómeno sin el análisis de la misma. En caso de la delegación enviada para parlamentar con los representantes de Nepete, que cayó del lado etrusco por la traición de una parte de la población de la comunidad $(6,10,2 ; 386$ a. C.); o de la legación enviada a la península Ibérica para tratar de convencer a los principes hispanos de traicionar su alianza con Cartago y establecer una entente con Roma $(21,22,1)$, por poner solo un par de ejemplos.

Como podemos comprobar, Roma utilizó profusamente la diplomacia en su proceso de expansión, tanto por la península Itálica como, después, por todo el Mediterráneo. Es sintomático y prácticamente una constante en el relato de Livio y otros autores que historiaron este proceso, el hecho de que uno de los primeros pasos que las autoridades romanas dieron al entrar en contacto con un territorio fuera comenzar a establecer relaciones diplomáticas con aquellos personajes que pudieran servir de interlocutores con las comunidades con las que los romanos contactaban en su proceso de expansión ${ }^{63}$. Es decir, se trataba de reconocer e identificar, primero y mantener contactos diplomáticos después, con aquellos personajes que representaran realmente a su comunidad y que tuvieran capacidad de influencia entre sus ciudadanos. No se trataba -o no, al menos, necesariamente- de mantener estos contactos con las instituciones o magistrados autorizados, sino con aquellos que realmente desempeñaban un papel relevante en la comunidad, esto es, por así decir, con sus voces autorizadas, al margen de que en ese momento desempeñaran un cargo de relevancia entre sus conciudadanos $^{64}$. De hecho, y viceversa, parece desprenderse de la obra de Livio que cuando ciertos pueblos o comunidades toman la iniciativa diplomática frente a Roma, dando el primer paso en distintas negociaciones con sus autoridades o representantes, los enviados seguramente sean las voces más autorizadas en su sociedad y no necesariamente sus magistrados electos - lo que tampoco tendría por qué implicar una descoordinación o independencia de acción de unos sobre otros-. Desde esta perspectiva, por lo tanto, los principes aparecerían aquí como aquellos personajes que tienen un poder real, de facto, entre sus conciudadanos.

Muy en relación con el contexto de expansión de Roma, Livio cita a ciertos principes que son objeto de castigo por parte de los romanos, ya sea por su oposición a la conquista romana o por ser cómplices de

este sentido, véase, para Hispania, los estudios pioneros de J. M. Blázquez Martínez (1967: 209-243) o de J. Mangas Manjarrés (1970: 485-513).

63. No obstante, la visión de primacía en las relaciones con otros pueblos por parte de Roma, así como la visión prácticamente unidireccional de estas relaciones ha sido criticada por algunos autores en los últimos años. Así, recientemente, véase por ejemplo E. Sánchez Moreno y T. Aguilera Durán (2003: 225-244).

64. En un sentido parecido al que aquí defendemos, véase F. P. Rizzo (1980: 211-221), en este caso analizando el mismo concepto en las Verrinas de Cicerón. 
una defección, en general tras haber pactado tratados de alianza con la capital del Lacio. Obviamente, el historiador patavino suele utilizar tales acciones para justificar el bellum iustum por parte de los romanos, tema al que dedicará numerosos esfuerzos y que es una constante a lo largo de su obra. Este sería el caso de los principales de Pomecia, auruncos ejecutados por los romanos, pese a ser rendida la plaza $(2,17,6 ; 502$ a. C.); de los cabecillas del movimiento sedicioso de Árdea, que prefirieron la alianza con los volscos rompiendo el pacto que mantenían con los romanos $(4,10$, 6; 443 a. C.); de los principales senadores de Atela y Calacia, en un número aproximado de setenta, ejecutados por los romanos en el contexto de la II Guerra Púnica $(26,16,6)$; también Marcelo recompensó y castigó a los principales de algunas ciudades sicilianas, según se hubieran opuesto o no a los romanos $(26,40$, 15); o Flaco, que vendía los bienes de los principes por haber defeccionado contra los romanos $(27,3,1)$; o de los principales de Regio, que fueron ejecutados por legionarios romanos por ser los cabecillas de una rebelión $(28,28,2)$; o Mandonio y otros jefes hispanos, que fueron entregados a los romanos y torturados por encabezar una revuelta $(29,3,4)$; o los principes tebanos condenados por los romanos $(42,46,8)$; o los 550 principes que fueron ejecutados en Demetriade por Licisco y Tisipo $(45,28,7)$.

Paralelamente, es muy frecuente que los romanos hicieran rehenes o prisioneros de guerra a lo largo del proceso de expansión, tanto por la península Itálica como por el Mediterráneo ${ }^{65}$. Este sería el caso, por ejemplo, de los trescientos jóvenes de las familias más ilustres de las ciudades volscas de Cora y Pomecia (2, 22, 2; 495 a. C.); de algunos de los jóvenes más importantes entre los latinos y los hérnicos, hechos prisioneros en una de las victorias romanas sobre los volscos $(6,13,7 ; 385$ a. C.); o de Hannón y algunos principes (¿cartagineses o hispanos?), que fueron apresados por Escipión tras su desembarco en Ampurias $(21,60,7)$; o Marcelo, que había preferido a un herrero y a un hispano como garantes de la entrega de Siracusa, antes que a los ciudadanos principales $(26,30,6)$; así como también de los principales ligures cautivos que desfilaron en el triunfo de L. Emilio Paulo (40, 34, 8). El objetivo de estas prácticas, extendidas entre todos los pueblos del Mediterráneo en la Antigüedad, fue básicamente dos: en el caso de los rehenes tener una garantía para que las cláusulas de los tratados o acuerdos firmados en este caso por Roma se cumplieran y, en el caso de los prisioneros, formar parte del botín de guerra como parte de las reparaciones que el vencido tenía que realizar a favor del vencedor de la contienda.

Para concluir el capítulo de las referencias a principes fuera del contexto de Roma en la obra de Tito Livio diremos que existen, además, otras acepciones del

65. Sobre esta distinción, véase D. Álvarez Pérez-Sostoa (2009: esp. 154 s.). concepto que el historiador patavino utiliza con menor asiduidad. Este es el caso de los principes amicorum de los reyes macedonios, esencialmente de Filipo V y de Perseo. En dicho contexto, princeps amicorum fue un título oficial, haciendo referencia a los principales amigos del entorno de la corte del rey ${ }^{66}$. Este fue el caso, por ejemplo, de Hipias, Midonte y Pantauco, principes amicorum del rey Perseo (42, 39, 7 y 44, 23, 2-9).

\section{REFLEXIONES FINALES}

En las páginas anteriores hemos tenido la oportunidad de analizar los distintos usos del concepto princeps en el $A b$ Urbe condita de Tito Livio. En primer lugar nos gustaría destacar que, pese a lo que en un primer momento pudiera parecer, Livio, como otros autores latinos, no utiliza -o al menos, no siempre-princeps/ principes para hacer referencia a personajes de los que se desconoce su estatus socio-político exacto, en especial cuando se refiere a pueblos o comunidades cuya constituciones e instituciones principales eran extrañas al historiador patavino. En este sentido, por lo tanto, Livio utiliza el concepto que estamos analizando bien de forma un tanto genérica, bien para calificar a personajes de los que conocemos sus carreras, así como el importante papel que desempeñaron en los distintos contextos históricos que narra el autor a lo largo de su obra.

En este sentido llama la atención que Livio use princeps para calificar a romanos que desempeñaron un papel especialmente destacado con mayor asiduidad en los primeros libros, desapareciendo prácticamente, al menos con esa acepción, tras la exposición de los primeros años de la historia republicana. Es cierto que Livio utiliza el calificativo a lo largo de toda su obra, pero en sus últimos libros lo hace prácticamente siempre con un valor genérico para referirse a un grupo de senadores más o menos destacados o, en un sentido más técnico, en un contexto militar para señalar a los soldados que se posicionaban detrás de los hastati en batalla. Es posible pensar que este hecho pueda deberse a que, al tratarse de episodios más remotos en la historia de Roma, nuestro historiador calificase así, de forma más genérica aunque con unas connotaciones bien definidas, a personajes de los que desconocía ciertos detalles con exactitud. No obstante, las fuentes que Livio pudo emplear para componer su Primera Década, especialmente los Anales Máximos o archivos de familias pertenecientes al patriciado y la nobilitas romana, quizás desaconsejen esta hipótesis ${ }^{67}$.

66. Es posible que Livio no supiera que se trataba realmente de

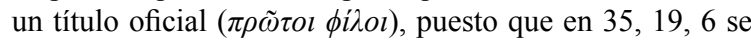
refiere a ellos como primos amicos, cfr. J. Briscoe (2012: 538).

67. Recordemos que, como el propio Livio afirmaba $(6,1,2)$ la historia más antigua de Roma quedaba entre tinieblas porque era infrecuente el uso de la escritura y porque muchos 
Otra característica que podemos deducir del uso de princeps/principes en la historia de Livio es que generalmente indica el rango del ciudadano principal (o principales) desde un punto de vista civil, pues nuestro autor también usa otros términos con connotaciones a priori más militares, como por ejemplo $d u x^{68}$. Pero, sin embargo, tampoco aquí se sigue una norma estricta, puesto que nuestro autor también utiliza el concepto en el sentido de «el que encabeza una fuerza militar», en especial en los primeros libros de las Décadas. No obstante, ambos significados no son excluyentes, pues en ocasiones el principal mando de una fuerza militar coincide con el personaje que debió desempeñar, al menos, uno de los principales roles civiles y políticos en su comunidad.

Paralelamente, cuando Livio usa el concepto desde un punto de vista civil, se refiere a una o varias personas con una influencia especial en un grupo humano definido, pero que no tienen por qué desempeñar puestos de relevancia en el momento en el que se narran los hechos. En este sentido, un magistrado puede ser denominado princeps indistintamente, pero un princeps no tiene por qué aparecer como un magistrado en el ejercicio de sus funciones ${ }^{69}$. En cualquier caso, debemos deducir que, cuando se trata de un número reducido de personalidades, Livio identifica en ellos un poder de persuasión e influencia especial en la opinión pública de sus comunidades y, especialmente, entre los organismos deliberativos cuya principal función es tomar decisiones que afectan a los intereses de Roma, ya sean estos asambleas, koina, senados u otras instituciones ${ }^{70}$ No hay que descartar tampoco que Livio usara el concepto que estamos analizando de una manera genérica para referirse a los magistrados de una determinada comunidad humana. En este sentido, debemos reconocer que es difícil que Livio conociera en profundidad cada uno de los sistemas políticos de las comunidades

documentos, entre ellos los commentariis pontificium -probablemente muy relacionados pero distintos a los Anales-, se perdieron en incendios. Además, como han puesto de manifiesto algunos especialistas, los Anales Máximos fueron poco utilizados -o, al menos, citados- por autores como Livio en el análisis de ciertos temas en los que dicha fuente debía ser crucial (cfr., al respecto, A. Rodríguez Mayorgas, 2007: 267 y n. 19). De hecho, es conocido que Livio debió tener a su alcance documentación que no consultó, centrando más sus fuentes en los historiadores que le precedieron. Sobre el método y las precauciones de Livio en la narración de los hechos más antiguos de la historia de Roma, véase G. Forsythe (1999: esp. 52 ss.) y, más concretamente para su relación con la tradición analística y las fuentes para la composición de las Primeras Décadas, P. G. Walsh (1961: esp 110-123) y J. Von Ungern-Sternberg (2015: 167 ss.), con abundante literatura.

68. En el mismo sentido, véase E. Melchor (2010: 177).

69. También E. García Riaza $(2019,230-232)$ o E. Melchor (2010: 178).

70. Cfr. J. F. Rodríguez Neila (1998: 117 s.) o E. Melchor (2010: 179). que aparecen en su obra y el funcionamiento institucional de las mismas y, si lo hizo, seguramente fue a través de otros autores que sí pudieron tener más familiaridad con la organización constitucional de ciertas comunidades $^{71}$. Todo ello, sin olvidar, además, el fuerte componente moral existente en la obra del patavino, quien sin duda empleó el concepto que hemos analizado para cualificar singularmente a muchos de los personajes que aparecen en su obra ${ }^{72}$.

En cuanto a las funciones que se le atribuyen a estos principes a lo largo de la obra liviana, pese a que en su conjunto son muy heterogéneas, cuantitativamente destacan sobremanera dos: los contextos en los que se narran luchas internas en una determinada comunidad cuyas consecuencias son favorables o perjudiciales para Roma y, en estrecha relación con estas, los contextos diplomáticos en los que representantes romanos en las provincias o el propio senado en Roma, deben negociar diferentes acuerdos con esas mismas comunidades. Así, son frecuentes los pasajes en los que Livio nos narra cómo los principes encabezaron defecciones o defendieron alianzas con los romanos. En este sentido, destaca los diferentes estados de opinión en las oligarquías de las distintas comunidades del mundo mediterráneo frente al expansionismo romano. Son interesantes las tendencias defendidas por estos personajes con la finalidad de salvaguardar sus intereses $\mathrm{y}$, con total seguridad, la privilegiada posición de la que gozaban en sus respectivas comunidades, incluso si ello suponía estar en contra de la mayoría de la opinión popular. No cabe duda de la existencia de un grupo de notables que prefirieron defender la alianza con Roma y, a medio o largo plazo la pérdida de cierta autonomía cívica, frente a otros que pensaron que lo mejor para sus intereses fue oponerse al expansionismo romano, en muchas ocasiones firmando alianzas con los principales enemigos de la $U r b s^{73}$. Unos y otros, dependiendo del resultado de los conflictos y guerras protagonizadas por Roma,

71. Nos referimos fundamentalmente a Polibio, usado de forma profusa como fuente por Livio, en especial, en la narración de los acontecimientos orientales. Obviamente, Polibio debió conocer de forma mucho más directa la organización de poleis, koina, etc. del ámbito helenístico. En este sentido, recordemos que Polibio pertenecía a la élite de su ciudad y participó activamente en la diplomacia del ámbito heleno en el primer tercio del s. II a. C., llegando, como antes que él su padre, a desempeñar el cargo de hiparco de la Liga Aquea en 170 a. C. Por desgracia, no contamos con una fuente cualitativa tan importante en el ámbito occidental y, especialmente, en los hechos acontecidos en Hispania, puesto que aunque el historiador megalopolitano vivió directamente algunos de los acontecimientos que narra, no pudo conocer con el mismo detalle el ámbito institucional ibérico o celtibérico. Sobre el tema, véase A. P. Marín Martínez (2012: 447-462) y L. Silgo Gauche (2010: 67-83).

72. P. G. Walsh, 1961: passim.

73. Un buen ejemplo en este sentido serían los cartagineses en el contexto de la II Guerra Púnica o los macedonios en el contexto de la II y III Guerra Macedónica. 
hubieron de negociar con las autoridades romanas el nuevo statu quo frente a la que se estaba convirtiendo en la nueva potencia del Mediterráneo ${ }^{74}$. Todo ello sin olvidar el interesante papel que desempeñaron numerosos pretores, cónsules y mandos del ejército romano en este contexto, promoviendo revueltas internas, defecciones o estados de opinión prorromanos siempre en defensa de los intereses de la ciudad lacial. Finalmente, el nuevo rol de las oligarquías locales o regionales en el Mediterráneo, dependió de su actitud y apoyo de los intereses romanos, con la conmoción que ello debió suponer en el medio y largo plazo en cuanto a la sociología de las élites indígenas se refiere.

Permítame el lector concluir este trabajo con el análisis de un testimonio que puede ser ilustrativo al respecto de buena parte de todo lo dicho anteriormente. Nos situamos en la II Guerra Macedónica, poco antes de la decisiva batalla de Cinoscéfalas del 197 a. C. que, como es conocido, supuso la victoria definitiva de los romanos frente a Filipo V. Según Livio $(33,16)$ al rey macedonio solo lo apoyaban los acarnanes, a cuyos líderes Lucio Quincio Flaminio convocó en Corcira, sembrando en ellos un germen de rebelión (initium quoddam ibi motus fecit). Una de las razones del mantenimiento de la alianza con Roma era el odio que los acarnanes profesaban a sus vecinos etolios, aliados de Roma. Fue convocada una asamblea en Léucade, pero, según el propio Tito Livio, ni acudieron todos los pueblos acarnanes, ni todos los que acudieron estaban de acuerdo en sus alianzas. Esta situación fue aprovechada por el pretor (esto es, arconte) Zeuxida y dos principes, Arquelao y Bianor (principes gentis ambo), para presentar una moción favorable a la alianza con Roma. Sin embargo esta iniciativa no gustó a los pueblos que no estaban representados y, aprovechando el malestar, Filipo mandó a dos notables promacedonios, Androcles y Equedemo (duo principes Acarnanum), que consiguieron anular el decreto y que sus promotores fueran condenados por traición. Ante esta situación Zeuxida, Arquelao y Bianor podían haber ido a Corcira al lado de los romanos -como, por otra parte, hicieron otros muchos personajes que también apoyaron alianzas con los romanos-, pero prefirieron presentarse ante la asamblea acarnana y consiguieron ser restituidos en sus respectivas dignidades, aunque no lograron volver a la alianza con Roma.

En definitiva, a partir de este testimonio podemos observar las disensiones internas de las comunidades que entraron en contacto con Roma, el oportunismo de las autoridades romanas para decantar la balanza a favor de sus intereses, la importancia de la diplomacia

74. Sobre este particular, véase el senatus consultum de Thisbae (IG VIII, 2225; cfr. Liv. 42, 12), en el que, tras las victorias del pretor C. Lucretius Gallus, se restituye a los exiliados que habían apoyado a los romanos y se castiga a los promacedonios con la venta de sus propiedades. Cfr. R. S. Bagnall y P. Derow (2003: . $\left.^{\circ} 45\right)$, con traducción del documento y comentario de su contexto histórico. y, sobre todo, el destacado y delicado papel de los principes en el difícil contexto histórico en el que se desenvolvieron y que puso en peligro la privilegiada posición de la que disfrutaban en su sociedad.

\section{REFERENCIAS}

Álvarez Pérez-Sostoa, D. (2009). El confinamiento de los prisioneros de guerra y rehenes en la Roma republicana. Veleia, 26, 153-171. Recuperado de: http://hdl.handle. net/10810/17369

Bagnall, R. S. y Derow, P. (2003). The Hellenistc Period: Historical Sources in Translation. Oxford: Blackwell Publishing. DOI: https://doi.org/10.1002/9780470752760

Blázquez Martínez, J. M. (1967). Las alianzas en la Península Ibérica y su repercusión en la progresiva conquista romana. RIDA, 14, 209-243.

Briscoe, J. (1973). A Commentary on Livy, Books XXXIXXXIII. Oxford: Oxford University Press. DOI: https://doi. org/10.1093/actrade/9780198147381.book.1

Briscoe, J. (1981). A Commentary on Livy, Books XXXIV$X X X V I I$. Oxford: Oxford University Press. DOI: https://doi. org/10.1093/actrade/9780198144557.book.1

Briscoe, J. (2008). A Commentary on Livy, Books 38-40. Oxford: Oxford University Press. DOI: https://doi. org/10.1093/actrade/9780199290512.book.1

Briscoe, J. (2012). A Commentary on Livy. Books 41-45. Oxford: Oxford University Press. DOI: https://doi. org/10.1093/actrade/9780199216642.book.1

Broughton, T. R. S. (1951-86). The Magistrates of the Roman Republic. 3 vols. New York - Atlanta: American Philological Association.

Dubouloz, J. y Pittia, S. (2009). La Sicile romaine, de la disparition du royaume de Hiéron II à la réorganisation augustéenne des provinces. Pallas, 80, 85-125. DOI: https:// doi.org/10.4000/pallas. 1774

Džino, D. (2010). Illyricum in Roman Politics. Cambridge: Cambridge Universitary Press. DOI: https://doi.org/10.1017/ CBO9780511675942

Eckstein, A. M. (2006). Mediterranean Anarchy, Interstate War, and the Rise of Rome. Berkeley - Los Angeles -London: University of California Press. DOI: https://doi.org/10.1525/ california/9780520246188.001.0001

Eckstein, A. M. (2008). Rome Enters the Greek East: From Anarchy to Hierarchy in the Hellenistic Mediterranean, 230170 BC. Oxford: Blackwell Publishing.

Eckstein, A. M. (2009). The Diplomacy of Intervention in the Middle Republic: The Roman Decision of 201/200 B.C. Veleia, 26, 75-101. Recuperado de: https://ojs.ehu.eus/index. php/Veleia/article/viewFile/1428/1068

Edmondson, J. (2014). Hispania capta: reflexiones sobre el proceso e impacto de la conquista romana en la Península Ibérica. En G. Bravo y R. González Salinero (Eds.). 
Conquistadores y conquistados. Relaciones de dominio en el Occidente romano (pp. 19-44). Signifer, monografías y estudios de antigüedad griega y romana, 43. Madrid - Salamanca: Signifer Libros.

Forthyse, G. (1999). Livy and Early Rome. A Study in historical method and judgment. Historia. Einzelschriften, 132. Stuttgart: Steiner Franz Verlag.

García Riaza, E. (2013). Crisis políticas en los núcleos de Occidente durante la época de la expansión romana. En L. Lamoine, C. Berrendonner y M. Cébeillac-Gervasoni (Eds.). Gérer les territoires, les patrimoines et les crises (pp. 384-401). Clermont-Ferrand: Presses Universitaires Blaise-Pascal.

García Riaza, E. (2016). Une institution politique dans le contexte de l'imperialisme romain: les conventus omnium sociorum dans les références hispaniques de Tite-Live. Ktema, 41, 243-261.

García Riaza, E. (2019). La coalición aquitana del 56 a. C.: configuración y liderazgo. En E. Sánchez Moreno y E. García Riaza (Eds.). Unidos en armas. Coaliciones militares en el Occidente antiguo (pp. 217-239). Serie Occidens, 2. Palma: Ediciones UIB.

Gómez Espelosín, F. J. (1995). Filipo V y la política interna beocia en la segunda mitad del s. III a. C. Polis, 7, 127-144.

Gruen, E. S. (1984). The Hellenistic World and the Coming of Rome. 2 vols. Berkeley - Los Angeles London: University of California Press. DOI: https://doi. org/10.1525/9780520351233

Hellegouarc'h, J. (1972). Le vocabulaire latin des relations et des partis politiques sous la République. Paris: Belles Lettres.

Levene, D. S. (2010). Livy on the Hannibalic War. Oxford: Oxford University Press. DOI: https://doi.org/10.1093/acpr of:oso/9780198152958.001.0001

López Salvà, M. (1990-1991). Reflexiones de Plutarco y de Dión de Prusa sobre las ciudades griegas del este y su relación con Roma. Faventia, 12-13(1-2), 25-36. Recuperado de: https://ddd.uab.cat/record/49756

Mangas Manjarrés, J. (1970). El papel de la diplomacia romana en la conquista de la Península Ibérica (226-19 a. C.). Hispania, 30, 485-513.

Marín Martínez, A. P. (2012). Los itinerarios de Polibio en Hispania y su visión de la actividad guerrera de los pueblos peninsulares. En G. Bravo y R. González Salinero (Eds.). Ver, viajar y hospedarse en el mundo romano (pp. 447-462). Signifer, monografías y estudios de antigüedad griega y romana, 37. Madrid - Salamanca: Signifer Libros.

Marotta, V. (2005). Conflitti politici cittadini e governo provincial. En F. Amarelli (Ed.). Politica e partecipazione nelle città dell'Impero romano (pp. 121-201). Roma: L'Erma di Bretschneider.

Melchor, E. (2010). Los senados de las comunidades no privilegiadas de Hispania (s. III a. C.-s. I d. C.). En L. Lamoine, C. Berrendonner y M. Cébeillac-Gervasoni (Dirs.). La praxis municipale dans l'Occident romain (pp. 175-185). ClermontFerrand: Presses Universitaires Blaise-Pascal.
Moret, P. (2002-2003). Los monarcas ibéricos en Polibio y Tito Livio. Cuadernos de Prehistoria y Arqueología Universidad Autónoma de Madrid, 28-29, 23-33. DOI: https://doi. org/10.15366/cupauam2003.29.002

Oakley, S. P. (1999-2005). A Commentary on Livy, Books $V I-X .4$ vols. Oxford: Oxford University Press. DOI (vol. 1): https://doi.org/10.1093/actrade/9780198152774.book.1; DOI (vol. 2): https://doi.org/10.1093/actrade/9780198152262. book.1; DOI (vol. 3): https://doi.org/10.1093/ actrade/9780199271436.book.1; DOI (vol. 4): https://doi. org/10.1093/actrade/9780199237852.book.1

Ogilvie, R. M. (1965). A Commentary on Livy. Books 1-5. Oxford: Oxford University Press. DOI: https://doi. org/10.1093/actrade/9780198144328.book.1

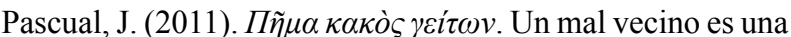
desgracia (Hes. Op. 346). La confederación helenística y la imagen de los beocios en el mundo romano. En J. M. Martín Copete, E. Muñiz Grijalvo y R. Gordillo Hervás (Coords.). Grecia ante los Imperios. V Reunión de historiadores del mundo griego (pp. 239-251). Spal Monografías, XV. Sevilla: Universidad de Sevilla, Secretariado de Publicaciones.

Pérez Rubio, A. (2019). Los más valientes de los galos: la coalición belga del 57 a. C. En E. Sánchez Moreno y E. García Riaza (Eds.). Unidos en armas. Coaliciones militares en el Occidente antiguo (pp. 163-216). Serie Occidens, 2. Palma: Ediciones UIB.

Rizzo, F. P. (1980). Principes civitatis nelle Verrine: realtà civica e idealità ciceroniana. En Ciceroniana IV, Atti del IV Colloquium Tullianum (pp. 211-221) Roma: Centro di Studi Ciceroniani. DOI: https://doi.org/10.13135/2532-5353/1516

Rodríguez Mayorgas, A. (2007). Antes de la historia: Anales Máximos, escritura y memoria en la Roma Republicana. Gerión, 25(1), 263-284. Recuperado de: https://revistas.ucm. es/index.php/GERI/article/view/GERI0707230263A/13966

Rodríguez Neila, J. F. (1998). Hispani principes. Algunas reflexiones sobre los grupos dirigentes de la Hispania prerromana. Cuadernos de Arqueología de la Universidad de Navarra, 6, 99-137. Recuperado de: https://revistas. unav.edu/index.php/cuadernos-de-arqueologia/article/ view/27788/23491

Rodríguez Neila, J. F. (2010). Legationes municipales en el oeste del Imperio y estatutos locales de Hispania. Algunas consideraciones. Mélanges de l'École Française de Rome, 122(1), 25-36. DOI: https://doi.org/10.4000/mefra.327

Sánchez Moreno, E. (2019). Carpetanorum, apendicibus olcadum vaccaeorumque centum ilia fuere: estrategias de asociación de las poblaciones meseteñas entre Cartago y Roma (220-185 a. C.). En E. Sánchez Moreno y E. García Riaza (Eds.). Unidos en armas. Coaliciones militares en el Occidente antiguo (pp. 71-104). Serie Occidens, 2. Palma: Ediciones UIB.

Sánchez Moreno, E. y Aguilera Durán, T. (2013). Bárbaros y vencidos, los otros en la conquista romana de Hispania. Notas para una deconstrucción historiográfica. En R. M. ${ }^{a}$ Cid López y E. García Fernández (Eds.). Debita Verba. Estudios en homenaje al profesor Julio Mangas Manjarrés, vol. 1 (pp. 225-244). Oviedo: Ediciones de la Universidad de Oviedo. 
Sanz, A.-M. (2015). La deditio: un acte diplomatique au cœur de la conquête romaine (fin du III ${ }^{\mathrm{e}}$-fin du $\mathrm{II}^{\mathrm{e}}$ siècle avant J.-C.). En B. Grass y G. Stouder (Eds.). La diplomatie romaine sous la République: réflexions sur une practique (pp. 87-105). Besançon: Institut des sciences et techniques de l'Antiquité (ISTA).

Silgo Gauche, L. (2010). La organización política de los íberos en la Segunda Guerra Púnica según Tito Livio y Polibio. Arse, 44, 67-83.

ThLL = Thesaurus Linguae Latinae. Recuperado de: http://publikationen.badw.de/de/000094373/pdf/CC\%20 BY-NC-ND/ThLL\%20vol.\%2010.2.2\%20col.\%20
$1233 \% \mathrm{E} 2 \% 80 \% 931970 \% 20 \% 28$ primaevus $\% \mathrm{E} 2 \% 80 \% 93 \mathrm{p}$ ropello\%29

Ungern-Sternberg, J. von. (2015). Livy and the Annalistic Tradition. En B. Mineo (Ed.). A companion to Livy (pp. 167-177). Blackwell Companion to the Ancient World, 155. Chichester - Malden: John Wiley \& Sons. DOI: https://doi. org/10.1002/9781118339015.ch13

Walbank, F. W. (1957-1979). A Historical Commentary on Polybius. 3 vols. Oxford: Clarendon Press.

Walsh, P. G. (1961). Livy. His Historical Aims and Methods. Cambridge: Cambridge University Press. 